\title{
Positioning of minipigs and its bearing on cervical vessels
}

\author{
S.M. Niehues ${ }^{\mathrm{a}, *}$, C. Müller ${ }^{\mathrm{b}}$, H. Hünigen ${ }^{\mathrm{b}}$, K. Dietze ${ }^{\mathrm{b}}$, J.K. Unger ${ }^{\mathrm{c}}$, F. Jung ${ }^{\mathrm{d}}$, B. Hamm ${ }^{\mathrm{a}}$ \\ and B. Hiebl ${ }^{\mathrm{e}}$ \\ ${ }^{a}$ Charité Universitätsmedizin Berlin, Department of Radiology, Hindenburgdamm 30, Berlin, Germany \\ ${ }^{\mathrm{b}}$ Institute of Veterinary Anatomy, Faculty of Veterinary Medicine, Freie Universitaet Berlin, Berlin, \\ Germany \\ ${ }^{\mathrm{c}}$ Department of Experimental Medicine, Charité Universitätsmedizin Berlin, Berlin, Germany \\ ${ }^{\mathrm{d}}$ Department of Clinical Haemostasiology and Transfusion Medicine, University of Saarland, \\ Homburg (Saar), Germany \\ ${ }^{\mathrm{e} C e n t e r}$ for Medical Basic Research, Martin-Luther-University Halle-Wittenberg, Halle (Saale), \\ Germany
}

\begin{abstract}
In this study, diameter and length of cervical vessels in minipigs of different ages were examined with respect to either prone or supine positioning. In addition, age related changes were established, since scanning of vessels was carried out at different stages of growth. Due to their early maturity, minipigs are used frequently as animal models for surgery or vascular interventions. To gain open access to cervical vessels the animals have to be in supine position. Since this does not correspond to a physiological position, changes in vessel length and inner diameter were measured. The results were compared to vessel length and diameter in the prone position, which represents the physiological position.

Contrast enhanced computed tomography (CT) was used for examination, which allowed for describing these changes in vivo without compromising the physiological pressure and condition. Significant changes could not be observed in the arterial system. However, the venous system showed significant changes $(p<0.05)$ in both vessel diameter and length. Moreover, results showed that development of the cervical vascular system is completed, when the minipigs are 17 months old.
\end{abstract}

Keywords: Computer tomography, minipigs, vessel

\section{Introduction}

Pigs are established animal models for experimental studies due to their cardiovascular anatomy and physiology [1-5], which shows a broad range of similarities to the cardiovascular system of humans [6]. For in vivo-studies, minipigs are frequently used since animal handling, housing and care are uncomplicated. Moreover, their limited growth rate compares to that of common farm pigs [7-9].

In biomedical research, minipigs are established animal models for vascular surgery and interventions $[2,10-13]$. However, only few systematic data on characteristics of the morphology of blood vessels are available, which would allow study planning and refinement according to the $3 \mathrm{R}$ principles of Russel and Burch [14]. Whereas corresponding blood vessels for living donor lung transplantation are established [15], a systematic approach to describe morphological characteristics of cervical arterial and venous vessels in minipigs are not available yet. In addition, existing data are mostly based on macroscopic ex-vivo necropsy studies and do not represent an in-vivo situation.

A major problem of all surgical procedures is the surgical approach, in which the vital parameters of the pigs have to be considered, especially the hemodynamic situation. Moreover, a fast, safe,

\footnotetext{
*Corresponding author: S.M. Niehues, Charité Universitätsmedizin Berlin, Department of Radiology, Hindenburgdamm 30, 12203 Berlin, Germany. Tel.: +49 308445 3041; Fax: +49 304502 6746; E-mail: Stefan.Niehues@ charite.de.
} 
and efficient intervention has to be accomplished. For open interventions of cervical vessels, minipigs have to be placed in supine position [16], while the physiological position of minipigs would be either standing, prone or flank recumbency. Usually, possible changes in vascular anatomy, which might be caused by non-physiological prone intraoperative placement, are not considered.

Thus, objective of this study was to evaluate in vivo-changes in length and diameter of the cervical vessels with regard to the positioning of the pig. These parameters were put into separate data groups in order to examine possible effects of age and/or body weight.

\section{Materials and methods}

\subsection{Study design}

18 minipigs were included in the study and stratified in three different groups (Table 1): Group one included 6 pigs, which were scanned before reaching maturity with a median age of 12 months and a median body weight of $29 \mathrm{~kg}$. Animals in group two and three were scanned twice. First, at the age of 17 months with a median body weight of $28 \mathrm{~kg}$ (group 2, $n=12$ ), and again at the age of 21 months with a median body weight of $35 \mathrm{~kg}$ (group $3, n=12$ ). All minipigs were examined by CT scanning first in supine followed by prone position.

\subsection{Animals and handling}

In vivo experiments were approved by the regional office for health and social welfare (LaGeSo) of Berlin and performed at the animal facility of the Charite University Clinic, Campus Virchow (Berlin, Germany), Department of Experimental Medicine (certified by ISO 9001:2008), on female pigs from the breed Göttingen ${ }^{\mathrm{TM}}$ Minipig (Ellegaard, Denmark). The principles of laboratory animal care according to the guidelines of the European societies of laboratory animal sciences were followed. Animals were housed in groups of 6 animals in an environmentally controlled room (12/12 light/darkrhythm, $19-23^{\circ} \mathrm{C}, 55 \pm 10 \%$ relative humidity).

\subsection{Anesthesia}

General anesthesia was performed prior CT-imaging. Food was withdrawn the night before anesthesia, but the animals had free access to water. The minipigs were premedicated by intramuscular (i.m.) injection with $0.5 \mathrm{ml}$ atropine (Atropinum sulfuricum, $1 \mathrm{mg} / \mathrm{ml}$, Eifelfango, Germany). General anesthesia was accomplished by by i.m. injection with ketamine (i.m., $27 \mathrm{mg} / \mathrm{kg}$, Ursotamin ${ }^{\mathrm{TM}}$, $100 \mathrm{mg} / \mathrm{ml}$, Serumwerk Bernburg, Germany), xylazine (i.m., $3.5 \mathrm{mg} / \mathrm{kg}$, Rompun ${ }^{\mathrm{TM}} \mathrm{TS}, 20 \mathrm{mg} / \mathrm{ml}$, Bayer Vital, Germany), and $3 \mathrm{ml}$ azaperone (i.m., Stresnil ${ }^{\mathrm{TM}}, 40 \mathrm{mg} / \mathrm{ml}$, Janssen Animal Health, Germany). In addition, an intravenous (i.v.) infusion with electrolyte solution (Ionosteril ${ }^{\mathrm{TM}}$, Fresenius, Germany, $1000 \mathrm{ml}$ ) was a) administered throughout the procedure.

Table 1

Group composition of the 18 pigs included in this study

\begin{tabular}{lcccc}
\hline & $\mathrm{n}$ & status & age [months] & body weight [kg] \\
\hline Group 1 & 6 & juvenile & $12 \pm 1$ & $29.4 \pm 4.5$ \\
Group 2 & 12 & pre-adult & $17 \pm 1$ & $28.3 \pm 3.0$ \\
Group 3 & 12 & adult & $21 \pm 1$ & $34.7 \pm 4.5$ \\
\hline
\end{tabular}




\subsection{Computer tomography $(C T)$}

To analyze the cervical vessels, contrast enhanced computed tomography (CT) of the pigs was performed in prone and supine position. CT scans were performed using a 64-slice scanner (LightSpeed $64^{\circledR}$; GE Medical Systems, Milwaukee, IL, USA).

The scan protocol used contrast-enhancement with automated intravenous injections of $120 \mathrm{ml}$ nonionic iodinated contrast medium $\left(\right.$ XenetiX $^{\odot}$ 350, Guerbet $\mathrm{GmbH}$, Germany) via the V. auricularis caudalis. Xenetix was used because it does not negatively influence micro- or macrocirculation [18].

Scan parameters were standardized (voltage $120 \mathrm{kV}$, maximal $600 \mathrm{~mA}$ with automatic mAoptimization at a noise index of 15 , mean $\mathrm{mA} 490$; collimated slice thickness: $64 \times 0.625 \mathrm{~mm}$; total detector width: $55 \mathrm{~mm}$; rotation speed: $0.4 \mathrm{~s}$; table feed per rotation: $55 \mathrm{~mm}$ ), resulting in a scan speed of approximately $3 \mathrm{~s}$ for $30 \mathrm{~cm}$ scan length in the z-axis.

For volumetric assessment, $1.25 \mathrm{~mm}$ images were reconstructed without overlap and evaluated. Basic image analysis was performed using Advantage Windows 4.2 (GE Medical Systems, Milwaukee, IL, USA), Amira (FEI, 5350 NE Dawson Creek Drive, Hillsboro, Oregon 97124 USA), and Visage 7.0 (Visage Imaging GmbH, Berlin, Germany).

\subsection{Evaluation procedures}

To analyze the influence of the animal positioning (prone, supine) on blood vessel length and luminal diameter, landmarks were defined for both parameters (see Table 2).

Table 2

Landmarks for the measurement of luminal diameter and length of biomedical relevant blood vessels

\begin{tabular}{|c|c|c|}
\hline \multicolumn{3}{|c|}{ Localization of measurements } \\
\hline Blood vessel & Luminal vessel diameter & Vessel length \\
\hline A. subclavia sinistra & at the outlet from the arcus aortae & $\begin{array}{l}\text { between the outlet from the arcus aortae to the } \\
\text { crossing of the first rib }\end{array}$ \\
\hline A. subclavia dextra & $\begin{array}{l}\text { at the outlet from the truncus } \\
\text { brachiocephalicus }\end{array}$ & $\begin{array}{l}\text { between the outlet from the truncus } \\
\text { brachiocephalicus to the crossing of the first rib }\end{array}$ \\
\hline Truncus bicaroticus & $\begin{array}{l}\text { just before the vessel splits up into the } \\
\text { Aa. carotides communes }\end{array}$ & $\begin{array}{l}\text { between its outlet from the A. subclavia dextra and } \\
\text { the A. carotis communis }\end{array}$ \\
\hline A. carotis communis & at the middle of the vessel length & $\begin{array}{l}\text { between its outlet from the truncus bicaroticus and } \\
\text { the A. carotis interna/externa }\end{array}$ \\
\hline A. carotis externa & $\begin{array}{l}\text { at the outlet from the A. carotis } \\
\text { communis }\end{array}$ & not measureable \\
\hline \multicolumn{3}{|l|}{ A. carotis interna } \\
\hline V. brachiocaphalica & at the inlet of the V. subclavia & $\begin{array}{l}\text { between the inlet of the V. subclavia and the V. cava } \\
\text { cranialis }\end{array}$ \\
\hline Vv. subclaviae & $\begin{array}{l}\text { just before the inlet into the V. } \\
\text { brachiocephalica }\end{array}$ & $\begin{array}{l}\text { between the crossing of the first rib and the inlet into } \\
\text { the V. brachiocephalica }\end{array}$ \\
\hline Vv. jugularis externae & at the middle of the vessel length & $\begin{array}{l}\text { between the point of confluence of the V. maxillaris, } \\
\text { the V. linguofacialis and the inlet of the V. subclavia }\end{array}$ \\
\hline V. jugularis interna & & not measureable \\
\hline V. cephalica & $\begin{array}{l}\text { just before the inlet into the V. jugularis } \\
\text { externa }\end{array}$ & not measureable \\
\hline
\end{tabular}




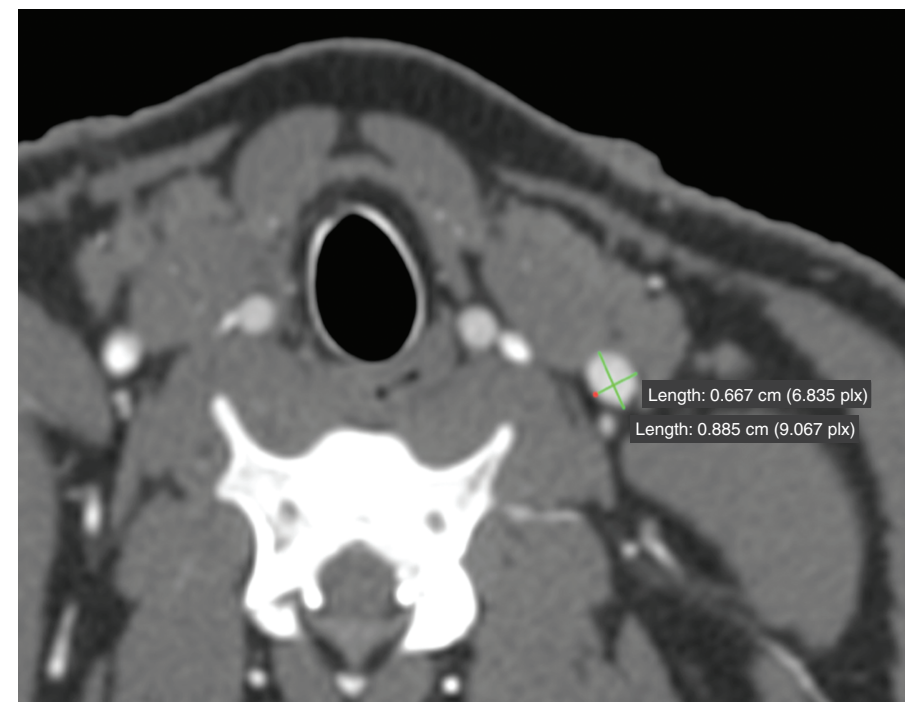

Fig. 1. Measurement of the diameter with two orthogonal lines in the vascular lumen.

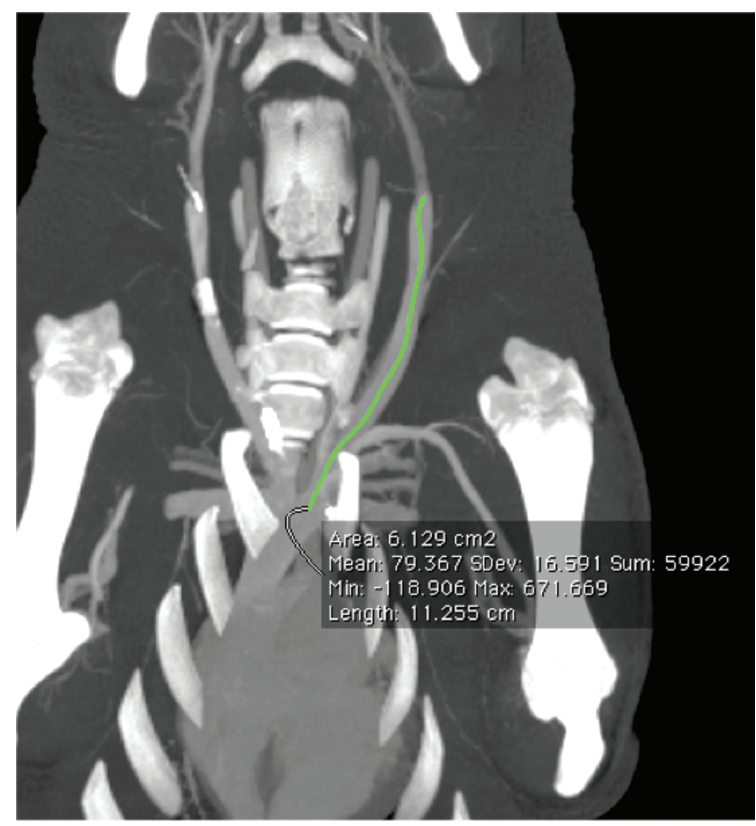

Fig. 2. Multiplanar reformation of the V. jugularis externa in supine position with centered measurement.

The vessel diameter was measured with two orthogonal lines at defined landmarks (see Fig. 1). The inner diameter was defined as the lumen filled with contrast media in the CT. Only the lumen was measured and the lumen did not include the vessel wall. Points of measurement were chosen perpendicular to the vessels axis.

For measuring the vessel length multiplanar reformations (MPR) were computed to ensure measuring the center of each vessel in its complete dimension (see Fig. 2).

To optimize visualization, three-dimensional images were constructed in volume rendering technique to display changes and dimensions of vascular filling. 


\subsection{Statistics}

All data were evaluated with Predictive Analytic Software (PASW Statistics18, SPSS, IBM). Standard analysis included minimum, maximum, median and standard deviation, and testing significance and visualization with box-and-whisker-plots.

For comparison of group 2 and 3 a paired sample $t$-test was used since the animals in both groups were identical. This test was also used to compare prone and supine position. For comparison between group 1 and 2/3, a $t$-test for independent samples was used. Significance level was set at $p<0.05$.

\section{Results}

\subsection{Vessel diameter}

There were no significant changes in vessel length and diameter between groups 2 and 3, even though weight of the animals had increased by 23 percent. Thus, groups 2 and 3 were pooled for further comparisons, since the vascular system was presumed to be fully developed. All vascular measurements in both resulting groups are shown in Tables 3-4.

\subsection{Comparing group 1 vs. $2 / 3$}

There were significant changes in vessel diameters between group 1 and group $2 / 3$ regarding the Vv. brachiocephalicae, Vv. jugularis externae and internae $(p<0.05)$. Vv. brachiocephalicae and Vv. jugularis internae showed an increase in size. As a specific characteristic, the Vv. jugularis externae showed a significant decrease in size when the pigs were between 12th and 17/21st month old (from median 10.8 to $9.1 \mathrm{~mm}$, standard deviation 0.3 and $0.4 \mathrm{~mm}$ ).

Changes in percentage of luminal decrease are shown in Table 5. Main differences between prone and supine positioning are present in the pre-adult and adult group with diameter reduction between 7.9 and 33.7 percent.

Table 3

Vessel diameter (in mm) of group 1, prone versus supine position; ${ }^{*}=p<0.05$

\begin{tabular}{lcccc}
\hline & $\begin{array}{c}\text { Prone } \\
\text { Median }\end{array}$ & Standard deviation & $\begin{array}{c}\text { Supine } \\
\text { Median }\end{array}$ & Standard deviation \\
\hline A. subclavia sinistra & 6.9 & 0.7 & 7.0 & 0.8 \\
A. subclavia dextra & 6.3 & 0.8 & 6.1 & 0.8 \\
Truncus bicaroticus & 8.0 & 0.6 & 7.9 & 0.8 \\
A. carotis communis & 5.3 & 0.8 & 5.7 & 0.7 \\
A. carotis externa & 5.2 & 0.7 & 5.2 & 0.7 \\
A. carotis interna & 1.8 & 0.3 & 1.9 & 0.5 \\
V. brachiocaphalica* & 9.4 & 1.0 & 8.8 & 0.8 \\
V. subclavia & 7.2 & 0.9 & 5.5 & 0.5 \\
V. jugularis externa* & 10.6 & 1.4 & 8.0 & 1.5 \\
V. jugularis interna* & 4.4 & 0.5 & 3.9 & 1.0 \\
V. cephalica & 4.9 & 0.9 & 4.5 & 0.7 \\
\hline
\end{tabular}


Table 4

Vessel diameter (in $\mathrm{mm}$ ) of group $\mathbf{2 / 3}$, prone versus supine position; ${ }^{*}=p<0.05$

\begin{tabular}{lcccc}
\hline & $\begin{array}{c}\text { Prone } \\
\text { Median }\end{array}$ & Standard deviation & $\begin{array}{c}\text { Supine } \\
\text { Median }\end{array}$ & Standard deviation \\
\hline A. subclavia sinistra & 7.6 & 1.0 & 7.7 & 1.3 \\
A. subclavia dextra & 6.6 & 0.8 & 6.5 & 0.9 \\
Truncus bicaroticus & 8.4 & 0.8 & 8.2 & 0.8 \\
A. carotis communis & 5.4 & 0.5 & 5.6 & 0.5 \\
A. carotis externa & 5.4 & 0.6 & 5.4 & 0.5 \\
A. carotis interna & 2.7 & 0.4 & 2.4 & 0.4 \\
V. brachiocaphalica* & 11.5 & 0.9 & 10.4 & 0.8 \\
V. subclavia & 6.7 & 0.5 & 5.2 & 0.7 \\
V. jugularis externa* & 8.8 & 1.2 & 5.9 & 1.5 \\
V. jugularis interna* & 4.9 & 0.6 & 3.3 & 1.0 \\
V. cephalica & 4.8 & 0.6 & 4.0 & 0.7 \\
\hline
\end{tabular}

Table 5

Percentage of reduction of vessel diameter after changing the positioning to supine

\begin{tabular}{lcr}
\hline Vessel & Group 1 (month 12) & Group 2/3 (month 17-21) \\
\hline V. brachiocephalica & $6.4 \%$ & $9.2 \%$ \\
V. jugularis externa & $17.6 \%$ & $22.2 \%$ \\
V. jugularis externa (middle part) & $24.9 \%$ & $32.6 \%$ \\
V. jugularis interna & $2.2 \%$ & $7.9 \%$ \\
V. jugularis interna (middle part) & $10.4 \%$ & $33.7 \%$ \\
V. cephalica & $7.3 \%$ & $15.8 \%$ \\
V. subclavia I & $19.9 \%$ & $27.2 \%$ \\
V. subclavia II & $20.1 \%$ & $26.1 \%$ \\
\hline
\end{tabular}

Table 6

Vessel length (in mm) measured in group 1 comparing prone and supine position, ${ }^{*}=p<0.05$

\begin{tabular}{lcccc}
\hline & $\begin{array}{c}\text { Prone } \\
\text { length prone vs. supine }\end{array}$ & Standard deviation & $\begin{array}{c}\text { Supine } \\
\text { Median }\end{array}$ & Standard deviation \\
\hline A. subclavia sinistra & 63.0 & 6.5 & 66.8 & 5.1 \\
A. subclavia dextra & 35.4 & 5.9 & 38.2 & 6.0 \\
Truncus bicaroticus & 11.8 & 2.8 & 12.9 & 3.6 \\
A. carotis communis & 113.5 & 10.8 & 116.0 & 10.0 \\
V. brachiocaphalica & 15.3 & 2.1 & 16.1 & 3.4 \\
V. subclavia & 15.3 & 1.2 & 17.6 & 1.8 \\
V. jugularis externa* & 90.0 & 8.3 & 94.9 & 7.6 \\
\hline
\end{tabular}

\subsection{Length}

Measurements of vessel length between the two different groups in both prone and supine position are shown in Tables 6 and 7: 
Table 7

Vessel length (in $\mathrm{mm}$ ) measured in group 2/3 comparing prone and supine position, ${ }^{*}=p<0.05$

\begin{tabular}{lcccc}
\hline length prone vs. supine & $\begin{array}{c}\text { Prone } \\
\text { Median }\end{array}$ & Standard deviation & $\begin{array}{c}\text { Supine } \\
\text { Median }\end{array}$ & Standard deviation \\
\hline A. subclavia sinistra & 66.0 & 8.2 & 67.1 & 9.6 \\
A. subclavia dextra & 34.6 & 4.5 & 37.5 & 5.9 \\
Truncus bicaroticus & 11.9 & 2.6 & 11.9 & 3.3 \\
A. carotis communis & 115.7 & 8.3 & 119.8 & 9.4 \\
V. brachiocaphalica & 15.3 & 3.0 & 15.6 & 4.4 \\
V. subclavia & 15.3 & 2.8 & 15.7 & 3.6 \\
V. jugularis externa* & 87.5 & 7.5 & 94.9 & 11.4 \\
\hline
\end{tabular}

Vessel length changes were found to be significant only in the external jugular vein with an increase in supine position with a median increase in vessel length of 5 percent in group 1 and 10 percent in group 2/3. All other veins also showed an increase in length when measured in supine position, but values were not significant.

\subsection{Comparison of prone vs. supine positioning}

Arterial vessels of the neck showed no significant changes between prone and supine position in all three groups. Slight differences were present, but did not reach levels of significance ( $p$-values between 0.07 and 0.7$)$.

In venous vessels, relevant changes in vessel diameter and especially in vessel length (Fig. 3) were found: vessel diameter change was significant in external and internal jugular, brachiocephalic, subclavian, and cephalic veins $(p<0.05)$ with vessel diameter decreasing in supine position.

\section{Discussion}

Even though a change of venous vessel diameter by positioning appears to be obvious, this fact can lead to severe consequences in experimental studies. As Barka et al. stated, supine position is the normal position to access cervical vessels during surgery [16]. In previous procedures involving anesthesia, surgery, or post-operative treatment each individual pig was placed in this unphysiological position for a certain period of time. During surgery, equipment is chosen according to the intraoperative situation, i.e. catheter or cuff size and length will be selected according to the vessel size. After surgery, the pig will recover from the intervention and will be housed for the study time according to its natural behavior, i.e. primarily in prone (standing) or lateral position. Devices adapted to the diameter used during surgery will reduce the vessel size (intentionally and unintentionally) and therefore potentially reduce the centripetal blood flow (Fig. 4).

Since decreased blood flow and changes of the vessel wall (catheter tip injury or direct surgical trauma, [17]) are two of the three general risk factors for thrombosis as postulated by Virchow (Virchow trias) an increase of thrombembolic events can be assumed. If these changes are performed on both sides venous stasis could result in serious tissue damage, bleedings, and obstruction.

Change in vessel diameter may be caused by the pressure within the vessel and in the pressure of the surrounding tissue. In supine position, the cervical musculature (M. sternocleidomastoideus) can produce traction on the venous vessels in prone position. As described in human medicine, the 


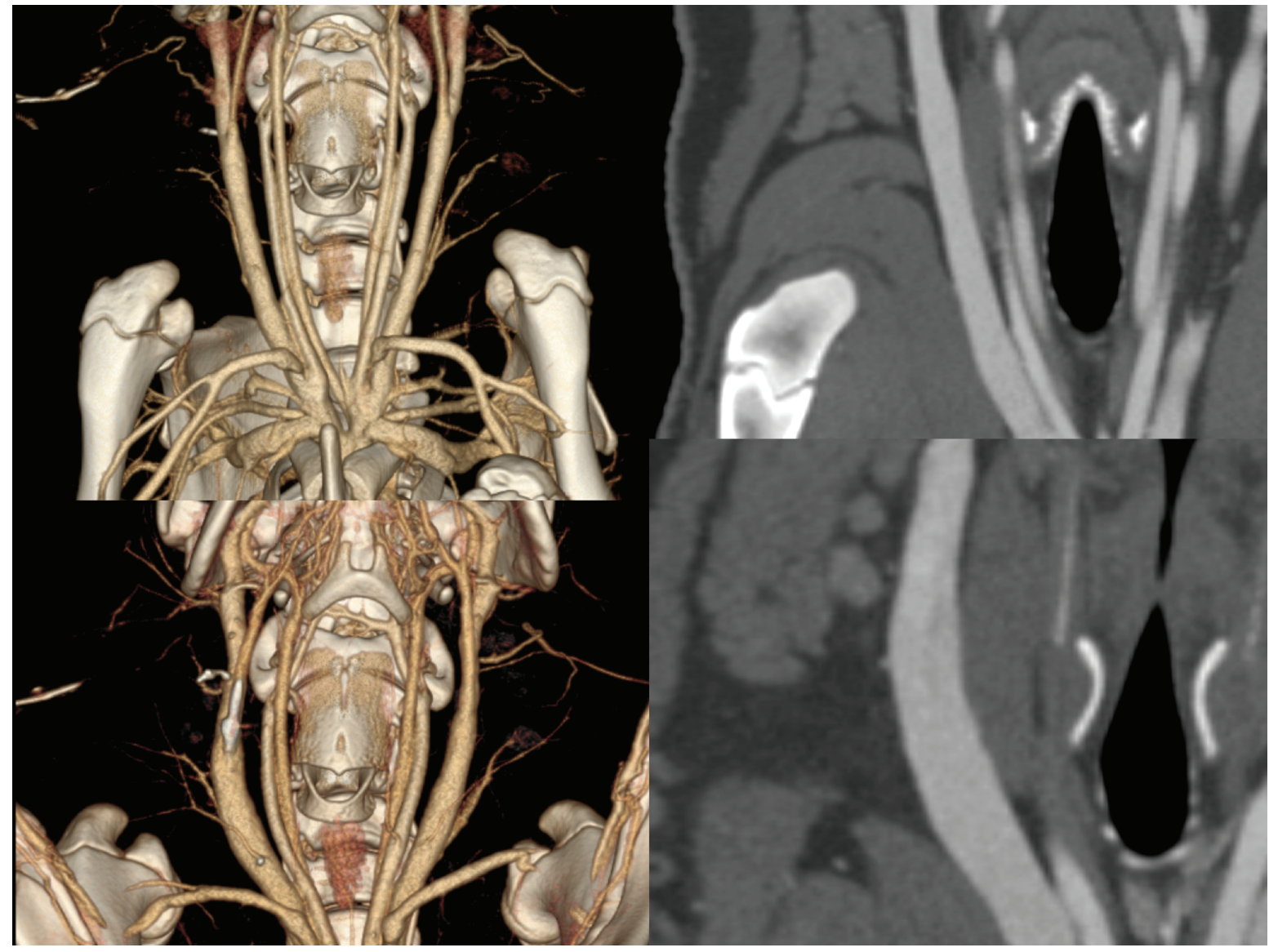

Fig. 3. Supine position (upper images) as VRT (left) and MPR (right) compared to prone position (lower images) displayed as VRT and MPR focusing on the external jugular vein.

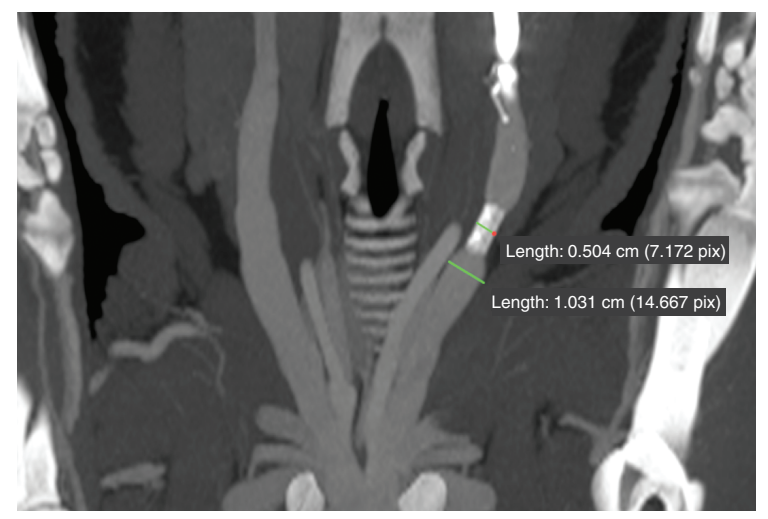

Fig. 4. Reduction of vessel size (48\%) in prone position due to an external venous cuff (reduction intended to confirm cuff mechanism stability). 


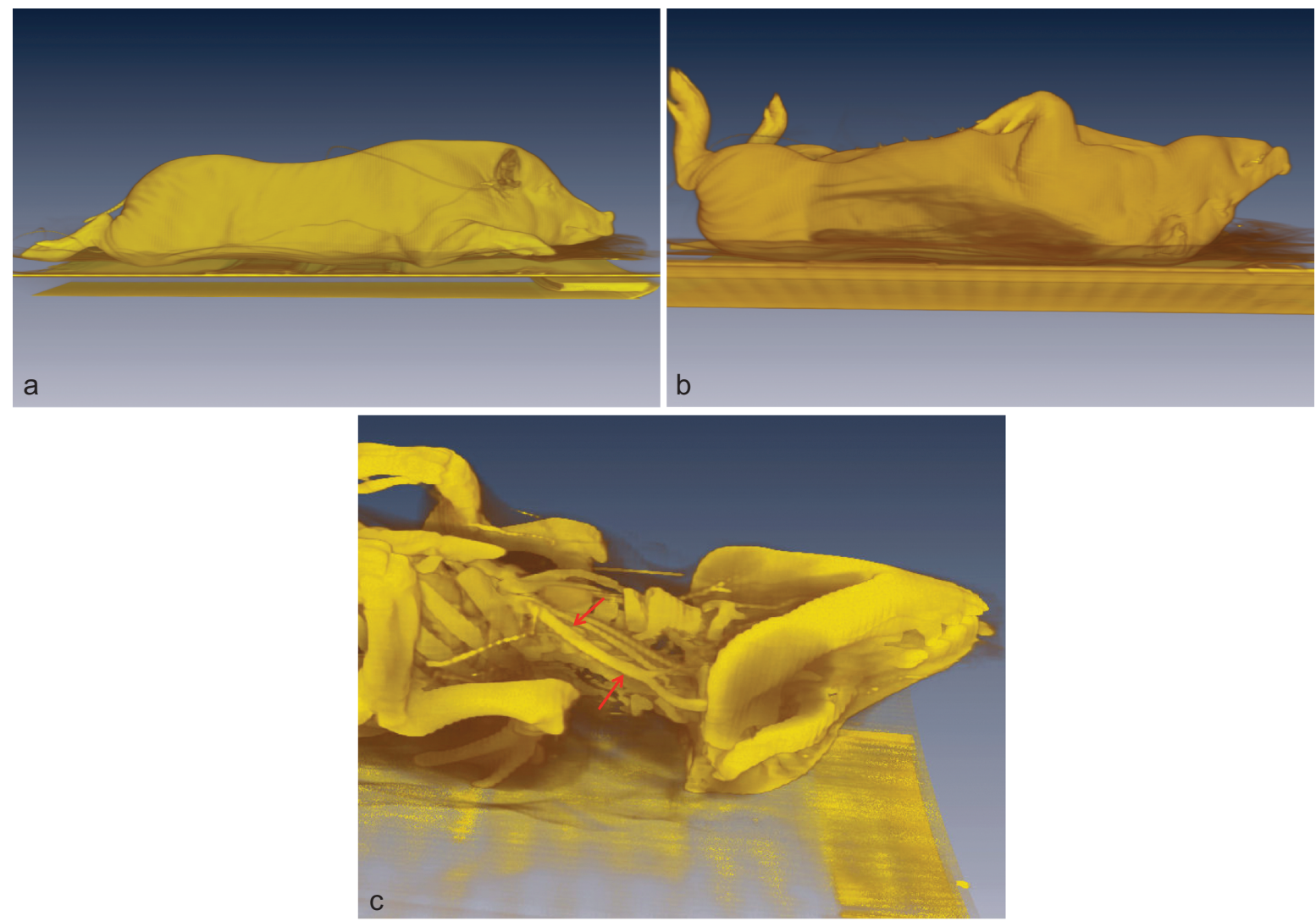

Fig. 5. a-c: Threedimensional rendering of a minipig a) scanned in prone position b) scanned in supine position c) showing the vessels stretched (arrows) in supine position.

jugular vein does not usually collapse due to traction of the surrounding tissue and tension of the musculature. In supine position, the musculature will produce pressure upon the vessels, which will, if the intraluminal pressure is less than the external pressure, result in compression. This effect will be augmented by the effects of sedation or even relaxation. The theory of tissue and vascular pressure also describes why arterial diameters are not affected in the same manner.

Whereas the change in diameter can be considered as a result of intraluminal and extraluminal pressure, vessel length should not be affected by this. Changes in vessel length can be explained by the positioning of the pigs. In supine position the head is inclined towards the neck (Fig. 5) causing tension along the z-axis consequently a stretched vessel. Due to this tension, the vessel diameter may be reduced as well. Thus, we suggest to put cushions underneath the head in supine position to reduce this effect.

Regarding vessel length, the arterial system is probably not affected by positioning due to its stiffness and large content of musculature in the vessel wall comprising the Tunica muscularis in arteries.

For vascular surgery (i.e. bypass surgery, vessel transplantation) the vessel in question should meet the criteria to fit in its new position, concerning both vessel length and size. Selecting the vessel according to the situation during surgery, there might be a mismatch when compared to the physiological condition. This error might result in significant changes in hemorheology, thrombosis, or even complete obstruction of the vessel, endangering the project itself.

However, these changes can be used on purpose to produce a stress model with intended luminal reduction or pressure on the vessel wall. 


\section{Conclusion}

Vessel diameter and length in minipigs change until the age of 17 months. After 17 months, the vascular system can be considered as fully developed.

Changing the position of the pig affects the vascular system: While arterial vessels do not change in vessel length and diameter with regard to the positioning of a minipig, the venous vascular anatomy shows significant changes in vessel diameter and vessel length. These changes can be used as a stress model for implanted material. However, they may also result in temporary obstruction or even thrombosis due to stasis within the veins. These changes have to be considered when choosing an adequate model for research and also adequate (surgical) treatment and material for projects focusing on cervical vessels. Moreover, the data provided here offers a database for diameter and length of cervical vessels in Göttingen minipigs in different stages of growth.

\section{References}

[1] Guerci P, Tran N, Menu P, Losser MR, Meistelman C, Longrois D. Impact of fluid resuscitation with hypertonichydroxyethyl starch versus lactated ringer on hemorheology and microcirculation in hemorrhagic shock, Clin Hemorheol Microcirc 2014;56:301-17.

[2] Kurz P, Stampfl U, Christoph P, Henn C, Satzl S, Radeleff B, Berger I, Richter GM. Self-expanding nitinol renal artery stents: Comparison of safety and efficacy of bare versus Polyzene-F nanocoated stents in a porcine model, Cardiovasc Intervent Radiol 2011;34:139-48.

[3] Shomura Y, Tanigawa N, Shibutani M, Wakimoto S, Tsuji K, Tokuda T, Terada J, Kariya S, Kojima H, Komemushi A, Sawada S. Water-soluble polyvinyl alcohol microspheres for temporary embolization: Development and in vivo characteristics in a pig kidney model, J Vasc Interv Radiol 2011;22:212-9.

[4] Wilson GJ. Interpreting arterial wall inflammation around stents in the porcine coronary artery model, J Vasc Interv Radiol 2011;22:260-1.

[5] Windt H, Kock H, Runge F, Hubel U, Koch W. Particle deposition in the lung of the Gottingen minipig, Inhal Toxicol 2010;22:828-34.

[6] Hughes GC, Post MJ, Simons M, Annex BH. Translational physiology: Porcine models of human coronary artery disease: Implications for preclinical trials of therapeutic angiogenesis, J Appl Physiol 2003;94:1689-701.

[7] Ma L, Shi Y, Chen Y, Zhao H, Gao C, Han C. In vitro and in vivo biological performance of collagen-chitosan/silicone membrane bilayer dermal equivalent, J Mater Sci Mater Med 2007;18:2185-91.

[8] Sangiorgi G, Arbustini E, Lanzarini P, del Bello B, Maestri M, Gaspari A, Solcia M, Virmani R, Inglese L. Nonbiodegradable expanded polytetrafluoroethylene-covered stent implantation in porcine peripheral arteries: Histologic evaluation of vascular wall response compared with uncoated stents, Cardiovasc Intervent Radiol 2001;24:260-70.

[9] Stampfl S, Stampfl U, Bellemann N, Sommer CM, Thierjung H, Radeleff B, Lopez-Benitez R, Berger I, Kauffmann GW, Richter GM. Biocompatibility and recanalization characteristics of hydrogel microspheres with polyzene-F as polymer coating, Cardiovasc Intervent Radiol 2008;31:799-806.

[10] Krug KB, Bovenschulte H, Geissler HJ, Flesch M, Schneider T, Brackrogge D, Reiter H, Heppelmann I, Christ H, Fischer JH, Lackner KJ. In-vivo measurements of coronary blood flow using 16-slice multidetector spiral computed tomography (MDCT) in a porcine model, Rofo 2009;181:220-9.

[11] Makris D, Holder-Espinasse M, Wurtz A, Seguin A, Hubert T, Jaillard S, Copin MC, Jashari R, Duterque-Coquillaud M, Martinod E, Marquette CH. Tracheal replacement with cryopreserved allogenic aorta, Chest 2010;137:60-7.

[12] Tang XF, Liu JJ, Wu YJ, Chen KM, Jin Y, Gao PJ, Zhu DL, Shen GX. Effect of hirulog-like peptide on balloon catheter injury-induced neointimal formation in femoral arteries of minipigs and relationship with inflammatory mediators, $\mathrm{J}$ Vasc Res 2010;47:262-9.

[13] Waltz X, Baillot M, Connes P, Gourdine JL, Philibert L, Beltan E, Chalabi T, Renaudeau D. Effect of heat stress on blood rheology in different pigs breeds, Clin Hemorheol Microcirc 2014;58:395-402.

[14] Russell W, Burch R. eds. The Principles of Humane Experimental Technique. 1959, Universities Federation for Animal Welfare

[15] Yoon W, Ryu JM, Lee MY, Moon YJ, Lee SH, Park JH, Yun SP, Jang MW, Park SS, Han HJ. 64-channel multi-detector row CT angiographic evaluation of the micropigs for potential living donor lung transplantation, J Vet Sci 2010;11:185-9. 
[16] Barka N, Rakow N, Lentz L, Kopcak M, Wika K, Menk A, Green M. Surgical approaches to vascular access for large-caliber devices in preclinical research models, J Am Assoc Lab Anim Sci 2010;49:472-4.

[17] McGurrin MA, Driscoll JL, Seifert KB, Brantley SG, Dagher FJ, Blackshear WM., Jr. Myointimal hyperplasia as a result of balloon-catheter thromboembolectomy, Arch Surg 1991;126:786-8.

[18] Bach R, Gerk U, Mrowietz C, Jung F. Influence of a new nonionic radographic contrast medium (iobitridol-350 versus $\mathrm{NaCl}$ ) on cutaneous microcirculation: Single-center, prospective, randomized, double-blind phase IV study in parallel group design, Microvasc Res 2000;60:193-200. 